\title{
Penetrating Glass Injury to the Sacral Spine
}

\author{
Eric R. Anderson, DO; Henry Irvin Grant III, MD; and Mark Weissman, MD
}

$\mathrm{P}$

enetrating injuries to the back present a challenge to the treating physician. Potential injuries to the spinal cord and retroperitoneal structures should be evaluated. Retention of the foreign body after a penetrating trauma is uncommon. A thorough physical examination along with proper imaging is imperative prior to removal of the retained object.

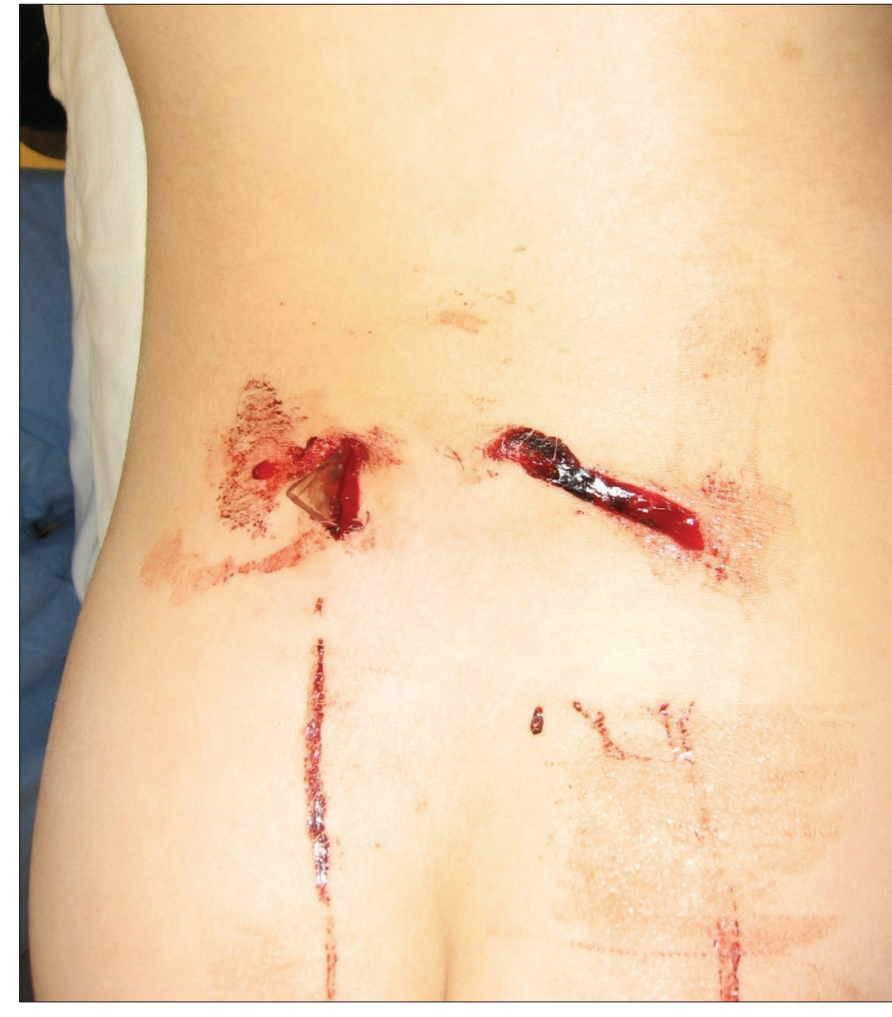

Figure 1. Glass shard embedded in the lower lumbar spine.
A six-year-old boy was climbing the ladder on his bunk bed when he fell into a window pane, landing on the sill with his buttocks. His father found him crawling on the lower bunk complaining of back pain. The father noted a fragment of glass penetrating the child's lower back. Emergency Medical Services were called and the boy was transferred to a level two trauma center. Physical examination revealed an immovable glass shard embedded in the lower lumbar spine, protruding $2 \mathrm{~cm}$ out of the skin, $2 \mathrm{~cm}$ left of midline (figure 1). Neurologic exam showed $5 / 5$ strength to the lower extremities with intact sensation to light touch and pinprick bilaterally. Triple-contrast computed tomography (CT) scan demonstrated a foreign body entering the skin at the level of the second sacral vertebrae (S2), entering the spinal canal at S3 and penetrating through the body of S3, with the tip exiting into the perirectal space (figure 2). No extravasation of contrast was noted. The patient subsequently underwent a S1-S2 laminectomy with retrieval of the foreign body (approximately $7 \mathrm{~cm}$ in length) (figure 3) and repair of a complicated dural laceration. Rigid sigmoidoscopy and postoperative $\mathrm{CT}$ scan were performed. No rectal injury was identified. The child recovered uneventfully and was discharged home on postoperative day four. He returned to school and normal physical activities eighteen days after surgery.

Keywords: Spine, Penetrating injury,
Surgery, Computed Tomography, X-ray

Received: March 17, 2010

Accepted: March 24, 2010

doi: $|0.3| 2 \mid / \mathrm{cmr} .2010 .927$

Tel: 7|5-387-5221

Fax:715-389-5757

Email: anderson.eric@marshfieldclinic.org

Tha Aperture, like the opening in the lens of a microscope that allows light to pass through, is a forum for art, humor, and images that provides a portal for new or different views of medicine and research. 


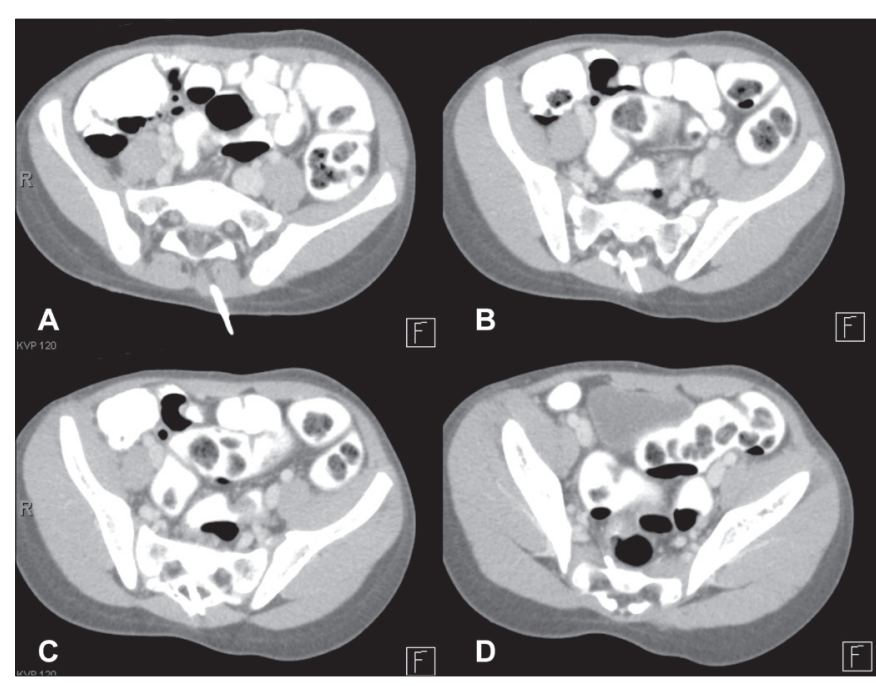

Figure 2. Triple-contrast computed tomography scan of abdomen and pelvis showing (A) glass entering the skin at S2, (B) glass penetrating the body of S3, (C) glass penetrating through the spinal canal at S3, (D) shard of glass exiting into the perirectal space.

Case reports involving penetrating glass injuries to the cervical, thoracic and lumbar spine have been described. However, on review of the literature, no reports of glass penetrating through the sacrum and spinal canal were found. Although rare, penetration of glass into the spinal canal requires a thorough radiologic evaluation, as retained fragments may be overlooked and the extent of injury may not be evident. ${ }^{1,2}$ Computed tomography is effective in evaluating the exact location and trajectory of the injury. ${ }^{3}$ Additionally, triple-contrast CT is both highly sensitive and specific for peritoneal violation and visceral injury, resulting in a decreased incidence of nontherapeutic laparotomy in penetrating torso trauma. ${ }^{4-6}$ Failure to remove a retained foreign body from within the spinal canal may result in cerebrospinal fluid leak, osteomyelitis, meningitis, migration

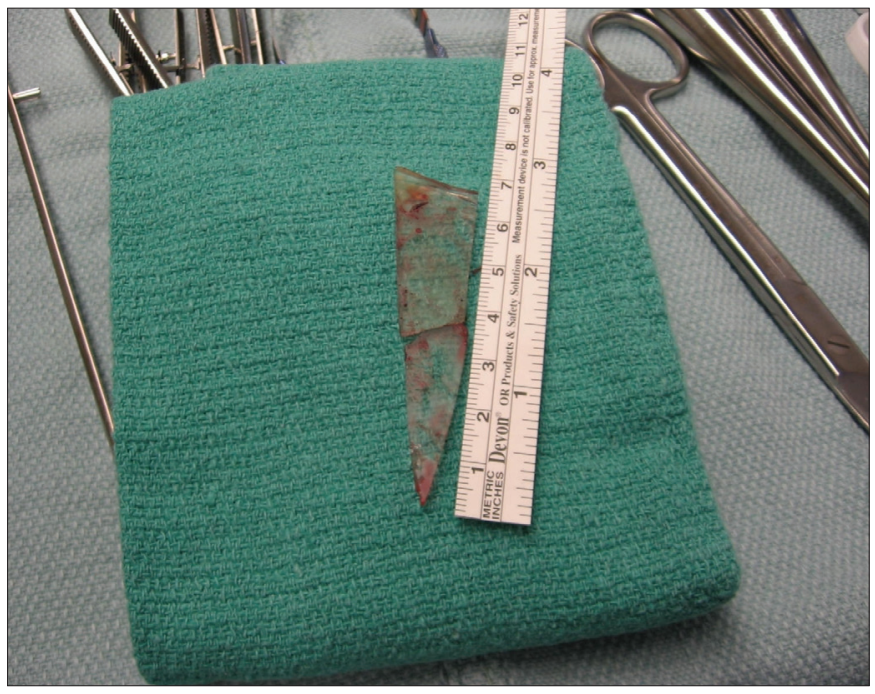

Figure 3. Glass shard after surgical retrieval. of the foreign body, and progressive neurologic deficits. ${ }^{7-9}$ This case exemplifies the need for a thorough evaluation of penetrating glass injuries to the back and spinal canal.

\section{References}

1. Baghai P, Sheptak P. Penetrating spinal injury by a glass fragment: case report and review. Neurosurgery 1982; 11:419-422.

2. Kahn J. The management of stab wounds to the back. J Emerg Med 1999; 17:497-502.

3. Shahlaie K, Chang D, Anderson J. Nonmissle penetrating spinal injury. Case report and review of the literature. J Neurosurg Spine 2006;4:400-408.

4. Chiu W, Shanmuganathan K, Mirvis S, Scalea TM. Determining the need for laparotomy in penetrating torso trauma: a prospective study using triple-contrast enhanced abdominopelvic computed tomography. J Trauma 2001;51:860-869.

5. Haan J, Kole K, Brunetti A, Kramer M, Scalea TM. Nontherapeutic laparotomies revisited. Am Surg 2003;69:562-565

6. Himmelman RG, Martin M, Gilkey S, Barrett JA. Triple-contrast CT scans in penetrating back and flank trauma. J Trauma 1991;31:852-855.

7. Manzone P, Domenech V, Forlino D. Stab injury of the spinal cord surgically treated. J Spinal Disord 2001;14:264-267.

8. Oertel M, Kreitschmann-Andermahr I, Ryang YM, Gilsbach JM,Korinth MC. The awakened intraspinal glass shard. Acta Neurochir (Wien) 2009;151:99-101.

9. Opel D, Lundin DA, Stevenson KL, Klein EJ. Glass foreign body in the spinal canal of a child: case report and review of the literature. Pediatr Emerg Care 2004;20:468-472.

\section{Author Affiliations}

Eric R. Anderson, DO*; Henry Irvin Grant III, MD*; Mark Weissman, MD†

*Department of General Surgery, Marshfield Clinic, 1000 North Oak Avenue, Marshfield, Wisconsin, USA

†Department of Neurosurgery, Marshfield Clinic, 1000 North Oak Avenue, Marshfield, Wisconsin, USA 